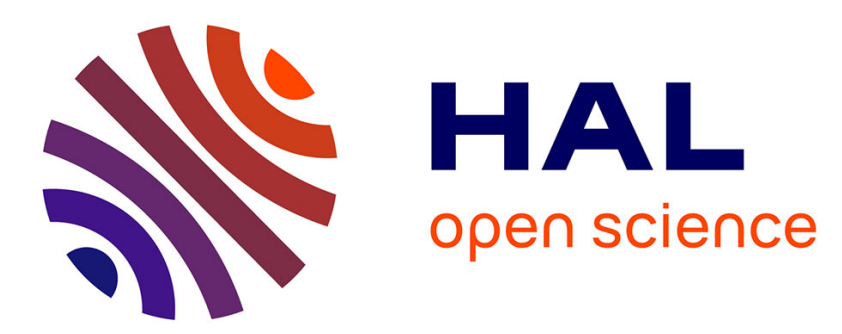

\title{
Exploiting Lean Benefits Through Smart Manufacturing: A Comprehensive Perspective
}

\author{
Elisa Mora, Paolo Gaiardelli, Barbara Resta, Daryl Powell
}

\section{To cite this version:}

Elisa Mora, Paolo Gaiardelli, Barbara Resta, Daryl Powell. Exploiting Lean Benefits Through Smart Manufacturing: A Comprehensive Perspective. IFIP International Conference on Advances in Production Management Systems (APMS), Sep 2017, Hamburg, Germany. pp.127-134, 10.1007/978-3319-66923-6_15. hal-01666206

\section{HAL Id: hal-01666206 https://hal.inria.fr/hal-01666206}

Submitted on 18 Dec 2017

HAL is a multi-disciplinary open access archive for the deposit and dissemination of scientific research documents, whether they are published or not. The documents may come from teaching and research institutions in France or abroad, or from public or private research centers.
L'archive ouverte pluridisciplinaire HAL, est destinée au dépôt et à la diffusion de documents scientifiques de niveau recherche, publiés ou non, émanant des établissements d'enseignement et de recherche français ou étrangers, des laboratoires publics ou privés. 


\title{
Exploiting lean benefits through smart manufacturing: a comprehensive perspective
}

\author{
Elisa Mora ${ }^{1}$, Paolo Gaiardelli ${ }^{1}$, Barbara Resta ${ }^{1}$, Daryl Powell ${ }^{2,3}$
}

1 CELS - Research Group on Industrial Engineering, Logistics and Service Operations,

Department of Management, Information and Production Engineering, Università degli Studi di Bergamo, viale Marconi 5, 24044, Dalmine (BG), Italy

\{barbara.resta; paolo.gaiardelli\}@unibg.it

2 Department of Industrial Economics and Technology Management, Norwegian University of Science and Technology, Trondheim, Norway

3 Kongsberg Maritime AS, Norway
daryl.j. powellentnu. no

\begin{abstract}
Lean Production has proven to be a valuable methodology to improve productivity while reducing costs. Notwithstanding the countless successful lean implementations in the extant literature, others highlight its limitations, especially in production environments characterized by demand volatility, high product mix and reduced lot sizes. Technology is seen by many as a potential solution to such limitations, especially in the last years, with Industry 4.0 becoming an emerging frontier for the smart factories of the future. However, studies about the relationship between lean and smart manufacturing are scarce and often anecdotal. Therefore, the proposed work aims to fill this gap by developing a comprehensive model that links these two perspectives and serves practitioners to achieve lean's core goals in smart factories.
\end{abstract}

Keywords: Lean Production; Smart Manufacturing; Industry 4.0; Lean and Smart Manufacturing.

\section{Introduction}

Lean Production, intended as the worldwide diffusion of the Toyota Production System, has proven to be a successful driver for the achievement of world class manufacturing performance levels both in medium and large enterprises [1]. Notwithstanding the countless benefits that lean management can bring into an organisation, academic studies revealed that lean performance are compromised in presence of demand fluctuations [2] and that lean practices are most likely to fail in non-repetitive systems [3] characterized by "high product variety and low volumes" [4]. As a means of dealing with such turbulences, many researchers and practitioners have attempted to find alternative solutions, proposing better responses in the application of technology to their lean systems, intensifying the debate between the so-called "lean purists" and those supporting the combination of technology with lean practices [5]. Indeed, on the one hand, "lean purists" can in some instances view technology as an enemy for human labor [6] as well as a waste in terms of unnecessary costs and uncertainty within the

adfa, p. 1, 2011.

(c) Springer-Verlag Berlin Heidelberg 2011 
company. On the other hand, "lean and technology supporters" believe that technology can be accepted in a lean system but only under the condition that it serves people and adds value to the process [7], for example in enabling problem-solving activities towards the achievement of lean's core goals. More recently, the diffusion of the new emerging frontier of Industry 4.0 has fueled this debate highlighting the existence of some hidden connections between these two perspectives. Given the nascent nature of the topic, existing scientific literature does not provide theoretical and empirical understanding of the lean and smart manufacturing overlap, including mutual supporting actions, benefits, as well as enabling and hindering factors. Therefore, this article aims at filling this gap by answering the following question: What are the connections between lean and smart manufacturing?

In the following section we present the adopted research methodology. Section 3 reports the findings of a literature review about lean production and Industry 4.0. Section 4 presents the theoretical model followed by its application to a case study of a manufacturing company presented in Section 5. To conclude, the last section presents the main research contributions and highlights further research directions.

\section{Research methodology}

The research relies on a four-step process. In the first stage, an extensive literature review was carried out on the topics under study (lean production and smart manufacturing), as well as on their relationships in order to build the theoretical model. Secondly, the model was populated by means of industrial data, gathered from secondary sources (i.e., companies' websites, videos, non-academic articles and other online documentation, etc.) with the aim of identifying how smart manufacturing solutions available on the market can enhance the implementation of lean practices. Finally, the model was applied to a real-time case study of a manufacturing company in order to test its applicability and enhance its validity.

\section{Literature review}

This section presents the dominant elements of lean production and smart manufacturing found in the literature, as well as the areas of integration.

\section{Lean Production}

Lean production is an approach that evolves multidimensionally and gathers a large variety of management tools and "inter-related and internally consistent practices" summarized into four lean bundles: Just-In-Time (JIT), Total Quality Management (TQM), Total Preventive Maintenance (TPM) and Human Resources Management (HRM). Proponents of lean production suggest that the four lean bundles should be considered as a unique system [8] and that benefits on operative performance come from the synergic application of all lean practices and principles [9]. 


\section{Lean Production and technology}

Literature reports many technological applications already in use in the industry that allow to reach high levels of lean manufacturing sophistication [5, 10]. For example, technology fastens information sharing in the supply chain, facilitating the relation with suppliers and reducing lead time [11]. Moreover, it supports preventive maintenance activities $[12,13]$ as well as quality management [10], continuous improvement processes and defect prevention [14]. Furthermore, traditional lean tools have been modified through advances in technology, such as the "e-Kanban" system [15] or "ConWIP" and "Polca" systems to sustain the pull production schemes [13]. Although lean manufacturing can be applied without using ICT, investments in Information and Communication Technology are essential to increase the levels of lean manufacturing improvements [16]. Since the majority of lean manufacturing practices are information-intensive [14], the use of IT enables the exploitation of information within the organization itself (and the overall supply chain) in order to eliminate many examples of waste [13].

\section{Industry 4.0 and Smart Manufacturing}

Industry 4.0, also known as the fourth industrial revolution, refers to technical integration of Cyber-Physical Systems (CPSs) in all industrial processes where "components and machines become smart and part of a standardized network based on the well proven internet standards" [17]. Driven by the diffusion of ICT (including internet), the concept has been spread through different terminologies such as Smart Manufacturing and Smart Factory. According to [18], nine key technologies characterise smart manufacturing: additive manufacturing, augmented reality, big data analytics, cloud computing cyber security, horizontal and vertical integration systems, Internet of Things (IoT), robotics and automation, simulation. The combination of these technologies enables the realization of a smart manufacturing system [17] as summarized in the following table.

Table 1. Main components of a smart production system

\begin{tabular}{|c|l|}
\hline Smart product & $\begin{array}{l}\text { A smart product is an intelligent product, conveniently equipped with sen- } \\
\text { sors that collects process data during production. In this way, the process } \\
\text { can be monitored in real-time. }\end{array}$ \\
\hline Smart operator & $\begin{array}{l}\text { A smart operator is an employee equipped with wearable smart devices } \\
\text { that allow him/her to get information inherent to his/her job. }\end{array}$ \\
\hline Smart machine & $\begin{array}{l}\text { A smart machine is an intelligent device that uses machine-to-machine } \\
\text { technology to make decisions and solve problems without human inter- } \\
\text { vention. }\end{array}$ \\
\hline Smart workstation & $\begin{array}{l}\text { A smart workstation assures reliable, economical and ergonomically pro- } \\
\text { cesses, through changing its configurations dynamically without any loss } \\
\text { of quality and productivity. }\end{array}$ \\
\hline Smart planner & $\begin{array}{l}\text { A smart planner allows a better management and coordination of produc- } \\
\text { tion activities, adopting IT as the main support technology. }\end{array}$ \\
\hline
\end{tabular}

Lean and Smart Manufacturing

Information about the relation between lean and smart manufacturing is scarce and often anecdotal. Some scholars defined smart manufacturing as an advancement of lean 
production driven by the increased complexity and the raising demand for customized products [19]. Therefore, lean production has been considered as the necessary prerequisite for Industry 4.0 [20]. On the contrary, other scholars view Industry 4.0 as an enabler for lean implementation in that it addresses several of the barriers associated with a traditional lean implementation [21]. To this end, [21] creates a framework that summarizes barriers and challenges for lean development, proposing some solutions through Industry 4.0 implementation. [17] also proposes a framework where Industry 4.0 solutions support lean production, but it is limited only to the evaluation of Kanban and Andon. As a mean of filling the gap between these two paradigms and providing evidence about the hidden potential of Industry 4.0 to exploit lean benefits, a comprehensive model that integrates all the four bundles of lean production with the dimensions characterising the Industry 4.0 manufacturing approach is proposed.

\section{The theoretical model}

\subsection{Model creation}

Given the definitions and findings reported in the above literature review, the model was constructed focusing the attention on the two macro dimensions of Lean Production and Industry 4.0, changing the perspective from a traditional to a smart point of view. In particular, the dimension "Lean Production" was articulated into the four lean bundles, as defined by [8], while the dimension "Industry 4.0" was divided into five sub-dimensions according to [17]. The model is presented in Figure 1.

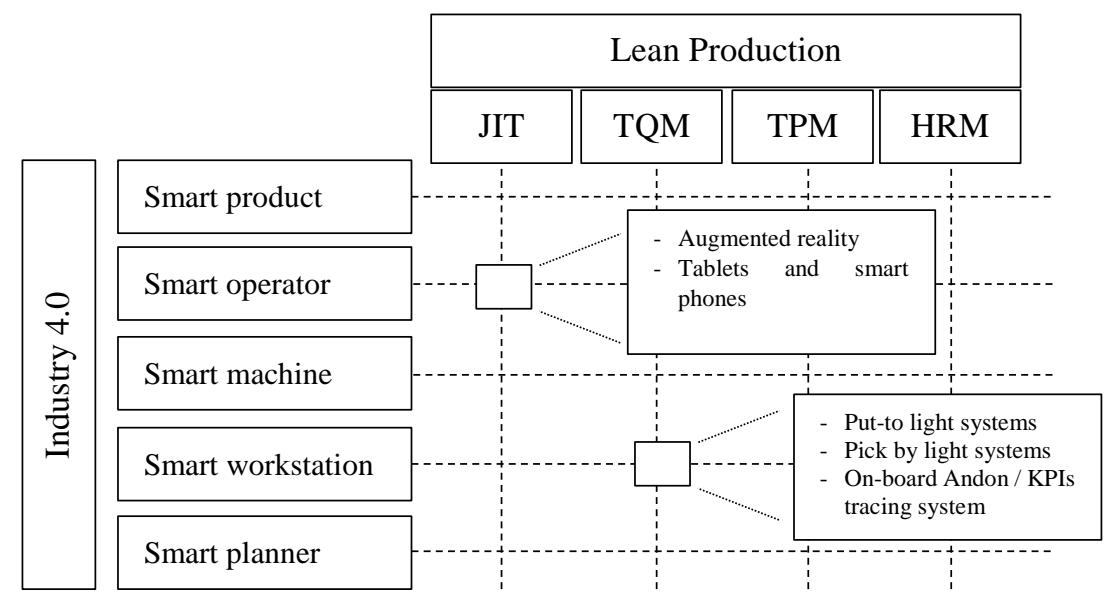

Figure 1-The theoretical model

\subsection{Populating the model}

The model was then empirically populated for analysing current solutions of smart manufacturing to enable lean implementation. In particular, it was filled using existing 
applications found on publicly available information collected from websites and company brochures. Some examples are reported below.

Smart Product. A product can provide through different sensors installed on board machines, operator, planners and workplaces all the information about its scheduling as well as its technical and production features. Achieved data can be re-elaborated through algorithms and analytics to improve process time (JIT) and quality (TQM), as well as to optimize equipment maintenance services (TPM). Moreover, real time information about product quality and lead times can support the implementation of training activities to improve operator capabilities in production (HRM).

Smart Operator. Augmented reality (i.e. smart glasses) enables continuous flow (JIT) and right assembly allowing error prevention (TQM), or support employees during preventive maintenance activities (TPM). In addition, smart devices make continuously available on the shop floor real-time KPIs, stimulating employees to empower their performances (HRM).

Smart Machine. A smart machine equipped with smart interfaces, can receive and send information about its production performances calling for fault-repair to avoid future break-downs (TPM) rather than low level of product quality (TQM). Moreover, smart interfaces installed on each single machine enable intra-communication across the production system, enhancing production and material handling efficiency and flexibility (JIT).

Smart Workstation. Smart devices in a workstation, by displaying working instructions through pictures and videos, can take the part of a poka-yoke system that can allow error detection (TQM) and training-on-the-job (HRM). Moreover, reconfigurable workstations re-adapt in real time on employees' characteristics and batch production requirements, so that lighting, font size and language can change in each work station on the basis of the worker characteristics (HRM). Finally, workplaces equipped with eKanban systems allow to exchange Kanban information making more efficient a production cycle (JIT).

Smart Planner. IT infrastructure allows to update Kanban to the new configuration requirements, synchronize dashboards with real-time data coming from the Gemba, as well as monitoring the sustainability and implementation of TPM activities. Thanks to IT infrastructure, the management can have continuously up-to-date information about the tasks performed by each employee in order to update the skill matrix.

\section{Case study}

Alpha is a medium-size company and world leader in the design of cooling units and dispensing systems for cold drinks. Although lean production brought important improvements in the initial stages of its implementation at Alpha, limitations soon emerged, especially in the assembly area that is characterized by a high product mix and variable batch sizes. In order to overcome these limits, the company moved toward Industry 4.0 by creating smart workplaces in the assembly lines in order to facilitate JIT activities, manage the high production variety and complexity and at the same time improve production process quality (TQM). On these premises, the first introduction of smart technologies in production in 2014 was eased by the affordability and availability 
of smart devices and the moderate investments required for app development. The project consisted on the introduction of some tablets to assist field-workers during assembly activities, as well as to support the production monitoring and problem identification. Each worker was then equipped with a tablet enabling pacing production through use of a takt-time counter available on the tablet interface. This option allowed the coordination of all the workers involved in the same line, establishing the rhythm of the production. A second technology was further introduced to support built-in-quality production, according to the Jidoka principle. In particular, the workplaces were equipped with an "Alert" system allowing any operator, in case of a problem, to stop the entire production line, call for the intervention of the technicians, support the intervention through an online root cause analysis, as well as track and trace maintenance and repair activities. As each field-worker becomes aware of the problems during the assembly and involved in the process improvement, the new technology allowed improvement of the workers problem-solving capabilities. Since the adopted technology initially presented some weaknesses that prevented the company from achieving its target performances, additional improvements were applied. In particular, intelligent mobile devices and algorithms were implemented to ease both on-the-job training activities and realtime performance monitoring. Thanks to the benefits provided by these tools, the activities of the shop floor were more transparent and easy to manage, allowing both fieldworkers and managers to concentrate on problem-solving activities to avoid production delays. The main changes were related to the introduction of a real-time and flexible scheduling system synchronized with work instructions and information on product configuration. The latter could be modified via web by each single operator. A specific algorithm was also implemented to show in real-time the trend of the main KPIs and turn them into valuable and actionable information. Finally, the system was developed to monitor each worker performance, updating his/her personal competences in a skills matrix in real time. The main smart applications introduced by Alpha to enable its lean manufacturing processes are reported in Figure 2.

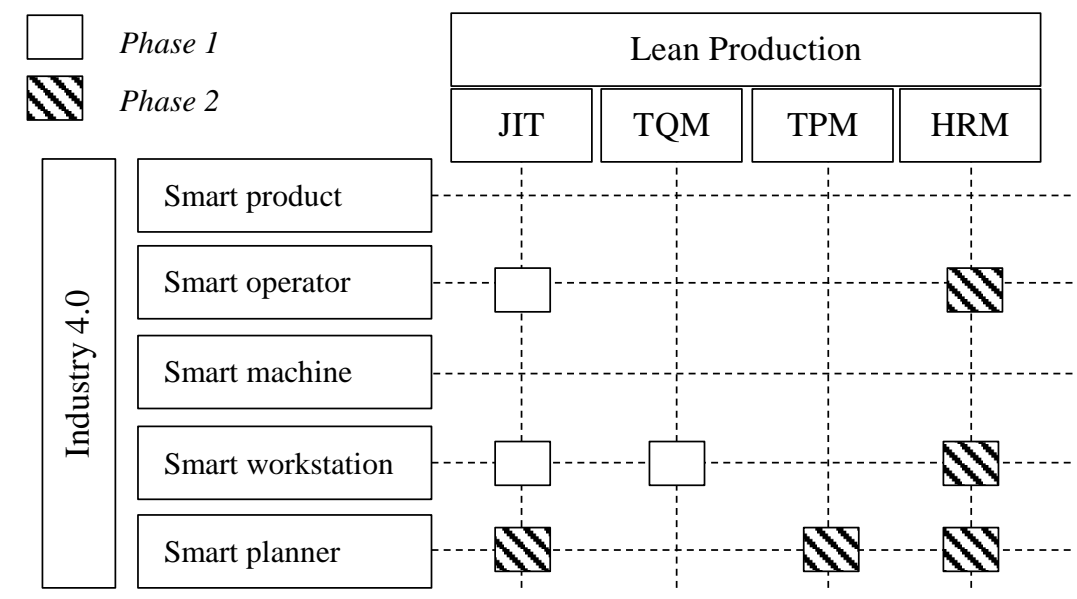

Figure 2 -Smart technologies for lean applications in Alpha 


\section{Conclusions}

The relationship between lean and technology has generated different debates in the last decades. The model developed in this paper proposes interesting insights into how implementing smart solutions can lead to the amplification of lean benefits.

From a theoretical point of view, the proposed model is a first attempt to integrate lean and smart manufacturing dimensions in order to explore how these two production paradigms, in the past considered as competing, can be applied synergistically to achieve superior performance. The model is useful for practitioners who face challenges with traditional lean implementations, especially in environments characterized by highly variable demand conditions and assembly complexity. The framework can be used both before and after a shift toward the smart factory, but a fundamental prerequisite is the fact that the organization should have already mastered and applied the lean philosophy. Regarding companies that have already implemented smart solutions, the framework is useful to support further lean transformation. This comprehensive framework provides an overview of the state of the art of the smart implementation and brings synergies within the organization thanks to the integration of multiple perspectives.

Notwithstanding, the model presents some limitations. First of all, it offers only a static representation of possible as-is and to-be situations, lacking details of the transformation process over time. Therefore, the creation of a dynamic model can increase its implementation. Secondly, some connections remain uncovered, and for this reason further case studies are encouraged to identify more solutions and add further examples to the framework.

\section{References}

1. Cua, K.O., McKone, K.E., Schroeder, R.G.: Relationships between implementation of TQM, JIT, and TPM and manufacturing performance. J. Operat. Manag. 19, 675-694 (2011).

2. Wan, H., Chen, F.F.: Decision support for lean practitioners: A web-based adaptive assessment approach. Computers in Industry 60, 277-283 (2009).

3. White, R.E., Prybutok, V.: The relationship between JIT practices and type of production system. Int. J. Manag. Sc. 29, 113-124 (2001).

4. Jina, J., Bhattacharya, A.K., Walton, A.D.: Applying lean principles for high product variety and low volumes: some issues and propositions. Log. Inf. Manag. 10 (1), 5-13 (1997).

5. Riezebos, J., Klingenberg, W., Hicks, C.: Lean Production and information technology: Connection or contradiction?. Com Ind. 60 (4), 237-247 (2009).

6. Sugimori, Y., Kusunoky, K., Cho, F., Uchikawa, S.: Toyota production system and Kanban system: materialisation of just-in-time and respect-for-human system. Int. J. Prod. Res. 15 (6), 553-564 (1977).

7. Liker, J.K.: The Toyota way: 14 management principles from the world's greatest manufacturer. New York: McGraw-Hill (2004). 
8. Shah, R., Ward, P.T.: Lean manufacturing: context, practice bundles, and performance. J. Operat. Manag. 21 (2), 129-149 (2003).

9. Womack, J.P., Jones, D.T.: Lean Thinking: Banish Waste and Create Wealth in Your Corporation. Simon \& Schuster, New York (1996).

10. Moyano-Fuentes, J., Jurado, P. J., Marín, J. M., Cámara, S.: Impact of Use of Information Technology on Lean Production Adoption: Evidence from the Automotive Industry. Int. J. Tech. Manag. 57 (1-3), 132-148 (2012).

11. Ward, P., Zhou, H.: Impact of Information Technology Integration and Lean/Justin-Time Practices on Lead-time Performance. Decision Sciences, 37 (2), 177-203 (2006).

12. Swanson, L.: Computerized Maintenance Management Systems: A Study of System Design and Use. Prod. and Inv. Manag. J., 38 (2), 11-15 (1997).

13. Riezebos, J., Klingenberg, W.: Advancing lean manufacturing, the role of IT. Computers in Industry, 60 (4), 235-236 (2009).

14. Perez-Arostegui, M. N., Benitez-Amado, J., Tamayo-Torres, J.: Information Technology-enabled Quality Performance: An Exploratory Study. Ind. Manag. Data Sys. 112 (3), 502-518 (2012).

15. Kotani, S.: Optimal method for changing the number of kanbans in the e-Kanban system and its applications. Int. J. Prod. Res., 45 (24), 5789-5809 (2008).

16. Morteza, G., Tang, S. H.: IT investments and business performance improvement: the mediating role of lean manufacturing implementation. Int. J. Prod. Res., 52 (18), 5367-5384 (2014).

17. Kolberg, D., Zühlke, D.: Lean Automation enabled by Industry 4.0 Technologies. IFAC Int. Fed. Aut. C. 48 (3), 1870-1875 (2015).

18. Russmann, M., Lorenz, M., Gerbert, P., Waldner, M., Jastus, J., Hengel, P., Harnisch, M.: Industry 4.0: The Future of Productivity and Growth in Manufacturing Industries. The Boston Consulting Group Report, April: (2015).

19. Kang, H.S., Lee, J.Y., Choi., S., Kim, H., Park, J.H., Son, J.Y., Kim, B.H., Noh, S.D.: Smart Manufacturing: Past Research, Present Findings, and Future Directions. Int. J. Prec. Eng. Man. Gr. Tech., Vol. 3, No. 1, pp. 111-128 (2016).

20. Berthold, M.: The evolution into a "Smart factory" - From knowing principles to conducting first use cases. Fraunhofer IAO, Stuttgart (2015).

21. Sanders, A., Elangeswaran, C., Wulfsberg, J.: Industry 4.0 Implies Lean Manufacturing: Research Activities in Industry 4.0 Function as Enablers for Lean Manufacturing. J. Ind. Eng. Manag. 9(3), 811-833 (2016). 